\title{
RESENHA/REVISIÓN/REVIEW
}

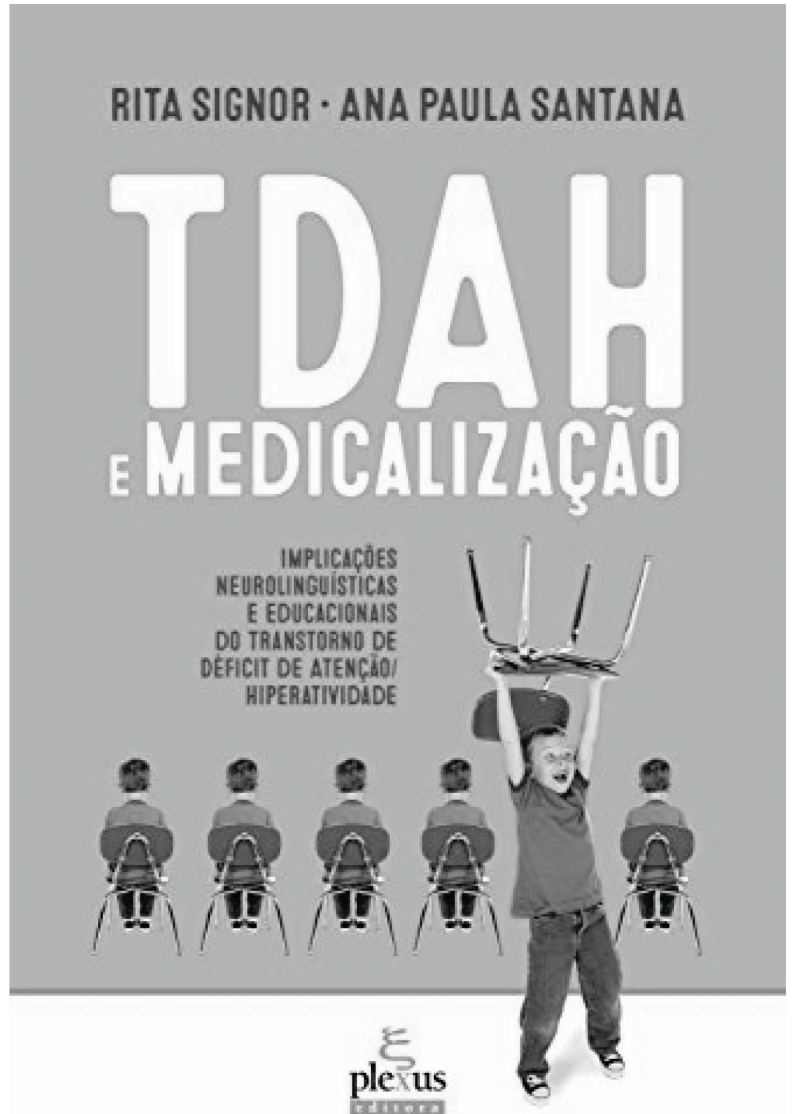

\section{TDAH E MEDICALIZAÇÃO: IMPLICAÇÕES NEUROLINGUÍSTICAS E EDUCACIONAIS DO DÉFICIT DE ATENÇÃO/HIPERATIVIDADE}

TDAH Y MECALIZACIÓN: IMPLICACIONES NEUROLINGÜÍSTICAS Y EDUCATIVAS DE ATENTIÓN/DÉFICIT DE HIPERACTIVIDAD

ADHD AND MEDICALIZATION: NEUROLINGUISTIC AND EDUCATIONAL IMPLICATIONS OF

ATTENTION/HYPERACTIVITY DEFICIT

Resenhado por:

Sandra Pottmeier*

Lais Oliva Donida**

Aline Olin Goulart Darde ${ }^{* * *}$

Universidade Federal de Santa Catarina

\footnotetext{
* Doutoranda pelo Programa de Pós-Graduação em Linguística da UfSC. Graduada em Letras e mestra em Educação pela FURB. É integrante do grupo de Estudos em Linguagem, Cognição e Educação (GELCE/UFSC). E-mail: pottmeyer@gmail.com

** Mestra e Doutoranda pelo Programa de Pós-Graduaça e em Linguística da UFSC. Graduada em Fonoaudiologia pela UFSC. É integrante do grupo de Estudos em Linguagem, Cognição e Educação (GELCE/UFSC). E-mail: lais.donida@gmail.com.

*** Mestra e Doutoranda pelo Programa de Pós-Graduação em Linguística da UFSC. Graduada em Educação Especial pela UFSM e em Fonoaudiologia pela UFSC. É integrante do grupo de Estudos em Linguagem, Cognição e Educação (GELCE/UFSC).E-mail: alineolin@yahoo.com.br.
} 
SIGNOR, R.; SANTANA, A. P. TDAH e medicalização: implicações neurolinguísticas e educacionais do déficit de atenção/hiperatividade. São Paulo: Plexus, 2016. 208p.

TDAH e medicalização: implicações neurolinguísticas e educacionais do Déficit de Atenção/Hiperatividade, de autoria de Rita Signor, mestra e doutora em Linguística pela UFSC, fonoaudióloga no Hospital Infantil Joana de Gusmão (Florianópolis/SC), e de Ana Paula Santana, fonoaudióloga, mestra e doutora em Linguística pela UNICAMP, professora do curso de Fonoaudiologia e da PósGraduação em Linguística da UFSC, busca "[...] discutir os aspectos neurolinguísticos, clínicos e educacionais atrelados à produção do chamado TDAH [...]” (SIGNOR; SANTANA, 2016, p. 17).

Este livro, publicado em 2016, destaca-se pela relevância do tema, uma vez que há ainda poucas produções interdisciplinares que tratem do Transtorno de Déficit de Atenção/Hiperatividade numa visão para além do diagnóstico clínico, ou seja, por meio de uma análise que considere o sujeito em sua dimensão histórico-cultural. A retomada do conceito de normal versus patológico no TDAH é constituída, no livro de Signor e Santana (2016), a partir de uma heterogeneidade de olhares, os quais entendem os sujeitos (crianças e adolescentes) como seres sociais, históricos e capazes. Trata-se, portanto, de uma leitura indispensável a estudantes, professores e pesquisadores que se interessam pela temática.

Disposta em 208 páginas, a obra é organizada em seis capítulos.

No primeiro capítulo, Atenção: um processo histórico-cultural, as autoras conceituam o que é atenção a partir dos estudos de Luria, que se baseia em um viés biológico e histórico-cultural. Para Luria, a atenção é “[...] a seleção da informação necessária [...]" para que a criança possa se desenvolver sendo mediada pelo outro (SIGNOR; SANTANA, 2016, p. 21). Nesse sentido, a atenção assume papel importante ao tornar-se produto de transmissão social e cultural, corroborando com o desenvolvimento da linguagem humana a partir das diversas práticas sociais. A argumentação construída pelas autoras demonstra profundo domínio teórico sobre os aspectos neurolinguísticos envolvidos. A discussão, pautada em uma abordagem da neurolinguística discursiva, não se resume a uma mera descrição dos processos neurocognitivos e linguísticos envolvidos, mas se torna crítica à medida em que as autoras contrapõem diferentes abordagens teóricas sobre a atenção e a linguagem, considerando, sobretudo, a dimensão social.

O segundo capítulo, Entendendo o TDAH, apresenta ao leitor como o diagnóstico é construído por aqueles que convivem direta e indiretamente com os sujeitos rotulados com TDAH. As autoras contextualizam a história do diagnóstico a partir de duas visões: uma organicista e homogeneizadora, pautada na condição biológica do sujeito, e a outra histórico-cultural, adotada por Signor e Santana (2016), a qual considera outros aspectos (sociais, culturais). Ao longo do capítulo, as autoras entrecruzam estudos sociológicos e etnográficos, como os de Bourdieu e Lahire, para discutir as relações sociais. Nesse sentido, o diagnóstico não pode se pautar única e exclusivamente a partir da visão biológica, pois há que se considerar as subjetividades que constituem a criança e as relações sociais estabelecidas.

O capítulo três, Medicalização, TDAH e Patologia da Atenção, discorre acerca do discurso dominante e historicamente legitimado do saber médico, que procura diagnosticar a todos aqueles que estariam fora de um padrão social. Como exemplo, as autoras trazem a esfera escolar em que as dificuldades de aprendizagem apresentadas pelos estudantes se constituem como patologias. Em alguns casos, a criança passa a ser tratada com uso de medicamentos no intuito de controlar a atenção e o comportamento que não atendem, sobretudo, às expectativas pedagógicas. As autoras reforçam que, na avaliação da criança como normal ou anormal, saudável ou doente, influem aspectos tanto sociais quanto ideológicos que vão além da psiquiatria ou do diagnóstico clínico. Ressaltam, ainda, que testes para aferir a inteligência da criança nos casos de TDAH, não contemplam questões sociais e culturais, baseando-se apenas em uma avaliação neuropsicológica isolada da realidade cotidiana. Neste capítulo, há a apresentação e a problematização dos testes e questionários utilizados para a avaliação, auxiliando o leitor a compreender como a avaliação é realizada e qual a finalidade de cada elemento avaliativo. De acordo com as autoras, "medicalizar é silenciar", o que intensifica a ocultação de problemas reais que estejam afetando a vida da criança e corroboram com as desigualdades sociais (SIGNOR; SANTANA, 2016, p. 66).

Em TDAH e Linguagem, quarto capítulo, Signor e Santana (2016, p. 75) assumem a concepção de que a linguagem em uma perspectiva histórica e cultural "[...] é constitutiva do sujeito e de todas as outras funções cognitivas [...]", o que implica afirmar que 
a linguagem e a atenção estão relacionadas às práticas sociais de leitura, escrita e oralidade da criança em todas as esferas sociais das quais ela faz parte. Signor e Santana (2016, p. 79) questionam ainda sobre o raciocínio de causa e efeito a partir da avaliação pautada na visão organicista, que acaba não contemplando "[...] as inserções culturais e as experiências mediadas que ampliam ou restringem o acesso à língua oral e escrita - e essa inserção tem implicações nos processos de aprendizagem [...]”. As autoras ressaltam que as avaliações diagnósticas partem de uma investigação positivista e reducionista direcionada para os déficits, compreendendo, assim, apenas capacidades isoladas, e acabam por classificar, rotular e até excluir os sujeitos diagnosticados dos grupos sociais por não corresponderem aos padrões tradicionais. Isso ocorre porque, nessas avaliações, não se compreendem os processos dialógicos que constituem o sujeito a partir desse contexto de aprendizagens sociais na e pela relação com o outro.

No quinto capítulo, O TDAH no contexto educacional, as autoras tomam como ponto de partida as políticas e leis de inclusão, as quais podem ajudar professores e demais envolvidos na esfera escolar a serem mais atentos às particularidades dos alunos. Entendem que a educação, a partir dessa perspectiva, acolhe estudantes com diferentes perfis na esfera escolar. Entretanto, isso não tem ocorrido exatamente como preconizam esses documentos, uma vez que o estudante que não se encaixa nos padrões do aluno "ideal", acaba sendo diagnosticado com algum transtorno funcional e excluído por práticas medicalizadoras. Atualmente, o que ocorre é que as crianças que têm chegado à escola já possuem maior contato com tecnologias digitais e, portanto, são "[...] mais ativas, mais responsivas, mais contestadoras [...]" (SIGNOR; SANTANA, 2016, p. 113). Contudo, neste espaço, "[...] a criança tem de se submeter a regras, permanecer sentada durante horas e fazer atividades tipicamente escolarizadas - como a realização de tarefas que requerem mais da função atentiva [...]” (SIGNOR; SANTANA, 2016, p. 111). Logo, quando a escola não considera "[...] aspectos relacionados ao letramento, às práticas de leitura da família, do sujeito e, sobretudo, dos docentes [...]” (SIGNOR; SANTANA, 2016, p. 110), corre-se o risco de contribuir com o discurso da legitimação a partir do diagnóstico. Ainda se ressalta que pode estar havendo, de certo modo, uma banalização dos "direitos aos diagnósticos", no sentido de não se vislumbrar o estudante numa perspectiva multicultural, diversa e que deve acolher a partir da singularidade. $O$ fracasso escolar estaria assim relacionado à patologização numa visão biológica/organicista, validando e justificando o TDAH em estudantes que encontram dificuldades na leitura e na escrita, e descartando os aspectos sociais imbricados nos processos de ensino e aprendizagem.

Em Como o TDAH se constrói: relato de casos, capítulo seis, Signor e Santana (2016) apresentam as histórias de Susi e Miguel. O diagnóstico de Susi é construído, inicialmente, a partir do seu comportamento na escola: era "agitada”, "desatenta”, "distraída", "falava muito". Essas características passaram a construir uma impressão de que Susi não se encaixava nos moldes da escola e estaria "fora dos padrões" naquela esfera social, o que implicaria o diagnóstico de TDAH. Ou seja, os discursos construídos ao longo do percurso de Susi, assim como seu afastamento do grande grupo em decorrência de seu comportamento, acabaram por não considerar outros aspectos sociais, culturais, afetivos constituintes da subjetividade e particularidade desse sujeito naquela instituição de ensino. Isso corrobora com o que preconizam Signor e Santana (2016), para quem as ações das crianças na esfera escolar ainda são avaliadas com base em uma perspectiva biológica ante a um viés histórico e social, não permitindo o erro ou comportamentos que sejam questionadores para aquele contexto. Nesse caso, foi somente a partir de um trabalho tomado de afetividade da professora, que Susi passou a ser alfabetizada e a ser compreendida.

Sobre a discussão acerca da construção do diagnóstico de Miguel, as autoras enfatizam sua constituição emocional, histórica, social até sua chegada na nova escola, marcada pelo abandono dos familiares biológicos. Esses aspectos acabam sendo ignorados pela escola quando o rotula por ser "inquieto", "distraído" e por apresentar dificuldades na escrita. Assim como Susi, Miguel questiona as regras impostas pela esfera escolar, e destoa do grupo pelo seu "comportamento". Além disso, o menino havia sido diagnosticado com Transtorno Opositor Desafiador, além de TDAH. As autoras pontuam que "[...] a criança que vivencia a patologização carrega emoções fortes, pois tem de lidar com situações muito estressantes. É excluída das relações, é vista e tratada como um ser anormal, é medicada, é rotulada, é controlada [...]" (SIGNOR; SANTANA, 2016, p. 169). É apenas durante as férias escolares que a mãe de Miguel não utiliza o medicamento prescrito, relatando não haver tido problemas com seu "comportamento". Ou seja, as ações que infringem as "regras", que caracterizam as patologias, que justificam seu controle por meio da medicação ocorrem somente durante o período escolar. Neste caso também, assim como no descrito anteriormente, uma professora compreende o sofrimento que perpassa a subjetividade do menino, tornando-se crítica aos diagnósticos e aos olhares aí naturalizados sobre Miguel. Ele passa, então, a ter condições de realizar atividades condizentes com a sua singularidade, a inseri-lo em demais contextos e a debater com 
os demais educadores e equipe escolar sobre os posicionamentos perante a criança, criando, assim, um ambiente escolar mais acolhedor e inclusivo ao estudante.

No processo diagnóstico dos dois casos analisados pelas autoras, ao desconsiderarem essas crianças como sujeitos sociais e históricos, o TDAH construiu-se como um distúrbio que os enquadrou, rotulou, diferenciou e excluiu nas relações com o outro. O diagnóstico é o primeiro olhar sobre esses sujeitos. As dificuldades de leitura, escrita, oralidade e afetivas observadas dentro da escola e que seriam compreendidas como processos normais dentro da relação entre ensino e aprendizagem, são intensificadas pelo rótulo do TDAH e tornam-se patológicas.

Por fim, as Considerações Finais apresentadas pelas autoras enfatizam a mudança de paradigma na compreensão sobre o TDAH, de uma visão exclusivamente neurobiológica, patológica, para uma problematização sobre a "era dos transtornos" e a "medicalização da educação" (SIGNOR; SANTANA, 2016, p. 187), observando como os transtornos são construídos socialmente a partir da interação entre os sujeitos. Ainda, ressaltam que "O problema, desse modo, não é o TDAH em si, mas as implicações geradas pela inserção da criança em processos medicalizadores" (SIGNOR; SANTANA, 2016, p. 189). Notam-se tensionamentos nas políticas públicas e também no ambiente escolar buscando "enquadrar" a criança que possui esse diagnóstico dentro do público da Educação Especial a partir de atendimentos educacionais especializados que são direcionados a outras condições funcionais, como as deficiências, nos quais têm se caracterizado como práticas medicalizadoras. Essas medidas podem intensificar os sentidos medicalizadores voltados ao TDAH, ampliando também o número de diagnósticos equivocados. Esse efeito cascata tende a ser prejudicial tanto em nível federal, no investimento em formação de professores e de profissionais da saúde para compreender esse fenômeno, quanto para os sujeitos, que passariam a ter suas subjetividades alteradas pelo controle através da medicação, bem como pela rotulação de quaisquer comportamentos pelo sentido patológico que o diagnóstico carrega.

Ao longo do texto, pode-se observar, contudo, que as autoras não negam que haja dificuldades relacionadas às crianças no interior das esferas sociais em que se encontram (como a escolar e a familiar, por exemplo), mas enfatizam que essas dificuldades - que são também, antes de tudo, sociais, emocionais, econômicas, culturais e até mesmo nas políticas - não são compreendidas como tais. Ou seja, as autoras deslocam o olhar antes voltado apenas para as questões biológicas, e lançam também para as condições externas aos sujeitos. Quando o olhar é restrito apenas às capacidades neurobiológicas sem a devida relação com aspectos de seu meio, surge a medicalização e a patologização dos sujeitos.

Esta obra, embora seja dirigida aos profissionais da saúde, educadores, estudantes e interessados pela temática, traz discussões teóricas por vezes muito distantes do público pretendido, pois apresenta uma linguagem que pode ser considerada técnica e densa em alguns momentos, como nos primeiros capítulos, o que a torna menos acessível a profissionais e estudantes pouco ou não familiarizados com o tema. Ao se utilizarem de situações cotidianas que ocorrem na prática clínica e/ou educacional, o leitor pode ter melhor vislumbre sobre a temática e os direcionamentos pedagógicos, terapêuticos e sociais dispostos pelas autoras ao longo do texto. Enfatiza-se, assim, a relevância de sua contribuição na compreensão desse fenômeno a partir de uma dimensão social, em função do aumento dos diagnósticos de TDAH no país e as reverberações que pode causar nas vidas dos sujeitos e na sociedade.

\section{() (1) $\circledast$}

Recebida em 22/11/2018. Aceita em 23/01/2019. 